\title{
A COMPARATIVE STUDY OF MANDIBULAR CYST ENUCLEATION USING THE PIEZOELECTRIC SURGERY VERSUS THE CONVENTIONAL TECHNIQUE
}

\author{
Yasmine A. Ibrahim ${ }^{l}$, Tarek M. Aly ${ }^{2}$, Hala R. Ragab ${ }^{3}$
}

\begin{abstract}
INTRODUCTION: piezosurgery device was originally developed for the atraumatic cutting of bone as it produces microvibrations and specific ultrasound frequency $(25-29 \mathrm{kHz})$. This new ultrasonic cutting method will be an alternative to conventional methods of oral surgery. OBJECTIVES: This study compares the use of piezosurgery and conventional technique in mandibular radicular cyst enucleation and this was estimated by clinical and radiographic analysis.

MATERIALS AND METHODS: This study was conducted on fourteen patients selected from the Out-patient Clinic of the Oral and Maxillofacial Surgery Department, Faculty of Dentistry, Alexandria University. Patients with radicular cyst in jaw region were diagnosed clinically and radiographically. The patients were randomly divided into two groups, seven patients were treated using piezosurgery and other seven patients were treated using conventional surgical procedures. Intraoperative and postoperative evaluation was carried out to monitor soft tissue damage, manipulation complexity, pain, infection and tissue dehiscence at $1^{\text {st }}, 2^{\text {nd }}, 7^{\text {th }}$ day and after one month postoperatively. The bone healing and bone density was determined radiographically after 3 and 6 months postoperatively using Cone Beam Computed tomography.

RESULTS: no soft tissue damage or manipulation complexities were observed in both groups, less bleeding was observed intraoperatively in piezosurgery group. Healing was uneventful with no signs of dehiscence in piezosurgery group with lower pain score than in control group. There was a significant decrease in the surface area of the bone defect in the piezosurgery group compared to control group along the follow up period. The improvement in the bone density was greater in the piezosurgery group than in the control group, with percent of difference $33.42 \%$ on the $3^{\text {rd }}$ month and $63.84 \%$ on the $6^{\text {th }}$ month.
\end{abstract}

CONCLUSIONS: Piezosurgery is effective in cyst enucleation as it accelerates bone healing and reduces intraoperative and postoperative complications.

KEY WORDS: Piezosurgery, radicular cyst, enucleation, Cone Beam Computed tomography.

1- Dentist, Faculty of Dentistry, Alexandria University, Egypt

2- Professor of Oral and Maxillofacial Surgery, Faculty of Dentistry, Alexandria University, Egypt.

3- Assistant Professor of Oral and Maxillofacial Surgery, Faculty of Dentistry, Alexandria University, Egypt.

\section{INTRODUCTION}

Odontogenic cysts are the most common form of cystic lesions affecting the maxillofacial region. They are classified traditionally into a developmental group, including keratocysts, dentigerous cysts, primordial cysts, gingival cysts and an inflammatory group including radicular cysts (13).

Radicular cysts are inflammatory jaw cysts at the apices of teeth with infected and necrotic pulps $(4,5)$. It is the most common cyst of the jaw. At radiography, most radicular cysts appear as round or pear-shaped, unilocular, lucent lesions in the periapical region (6). The main principle in treating cysts is to completely remove the cystic epithelium and its contents without damaging its integrity. Enucleation is defined as a complete removal of the cystic lining with healing by primary intention. It is the treatment of choice for most jaw cysts. The small remaining cavities after enucleation could be healed spontaneously by the normal bone healing mechanism (7).

Surgical burs can cut bone very effectively however; they can cause perforation of the cyst lining, laceration of soft tissues or burns if the surgeon doesn't pay attention. In addition, these rotating instruments are loud and produce macro vibrations during osteotomy which lead to fear and stress in patients when surgery is performed under local anesthesia (8).

Osteotomy performed using ultrasonic surgery was first described by Horton et al (9) in 1975, and in 2001,
Vercelotti et al (10) developed an ultrasonic surgical device which uses a modulated ultrasonic frequency that permits highly precise and safe cutting of hard tissue, nerves, vessels and soft tissues are not injured by micro vibrations (60 to $200 \mathrm{~mm} / \mathrm{sec}$ ), which are optimally adjusted to target only mineralized tissues, also it performs a better visualization of the surgical field.

Piezoelectric bone surgery seems to be more efficient in the first phases of bony healing; it induces an earlier increase in bone morphogenetic proteins, controls the inflammatory process better, and stimulates remodeling of bone as early as 56 days after treatment (11).

The use of piezosurgery for the treatment of jaw cysts and tumors is a new development and only a small number of applications have been reported in the literature. One clear advantage of piezosurgery over conventional techniques is that it allows for careful removal of the thin bone lamina that covers the cyst and the meticulous handling of the cyst without tearing the epithelial wall. This may result in a reduction in the rate of postoperative recurrence and complications $(12,13)$.

In view of this possibility, this study examined the intraoperative and postoperative results obtained using a piezosurgery device in radicular cyst enucleation and compare these results with those of conventional surgery. 


\section{MATERIALS AND METHODS}

\section{Patient selection and evaluation}

This study was conducted on fourteen patients who were selected from those referred to the out-patient clinic of Oral and Maxillofacial surgery department, Faculty of Dentistry, Alexandria University. All patients were diagnosed for having periapical mandibular cyst and indicated for surgical treatment by enucleation. They also were examined clinically and radiographically for evaluation of lesion size and its relationship to the important anatomical structures.

The inclusion criteria of this study were; patients who are confirmed by diagnosis to have mandibular radicular cyst with labial bone about $2 \mathrm{~mm}$ in thickness and having adequate oral hygiene. While the exclusion criteria were; systemic diseases that contraindicate surgical treatment such as uncontrolled diabetes mellitus, bleeding disorders, cardiac arrhythmia, patients on pace makers, mental disorders and any habits that might reduce blood flow and reduce healing as heavy smokers and alcoholism.

The patients were randomly divided into two groups, each group included seven patients:

1. Study group: the osteotomy for access to the cyst was implemented with piezosurgery device.

2. Control group: the osteotomy for access to the cyst was implemented by conventional technique using micromotor.

Preoperative clinical examination was performed for all patients: Patients data were collected; name, gender and age, medical and dental history were taken and the oral mucosa overlying lesion was examined for color, texture, firmness and thickness. Also, preoperative evaluation for all patients included panoramic $\mathrm{x}$-ray and cone beam computerized tomography (CBCT), to evaluate site and extent of the cyst, teeth related to the cyst, dimension of the cyst, thickness of labial bone and relation of the cyst to the vital structures (figure 1). All the teeth involved in the lesion were endodontically treated preoperatively.

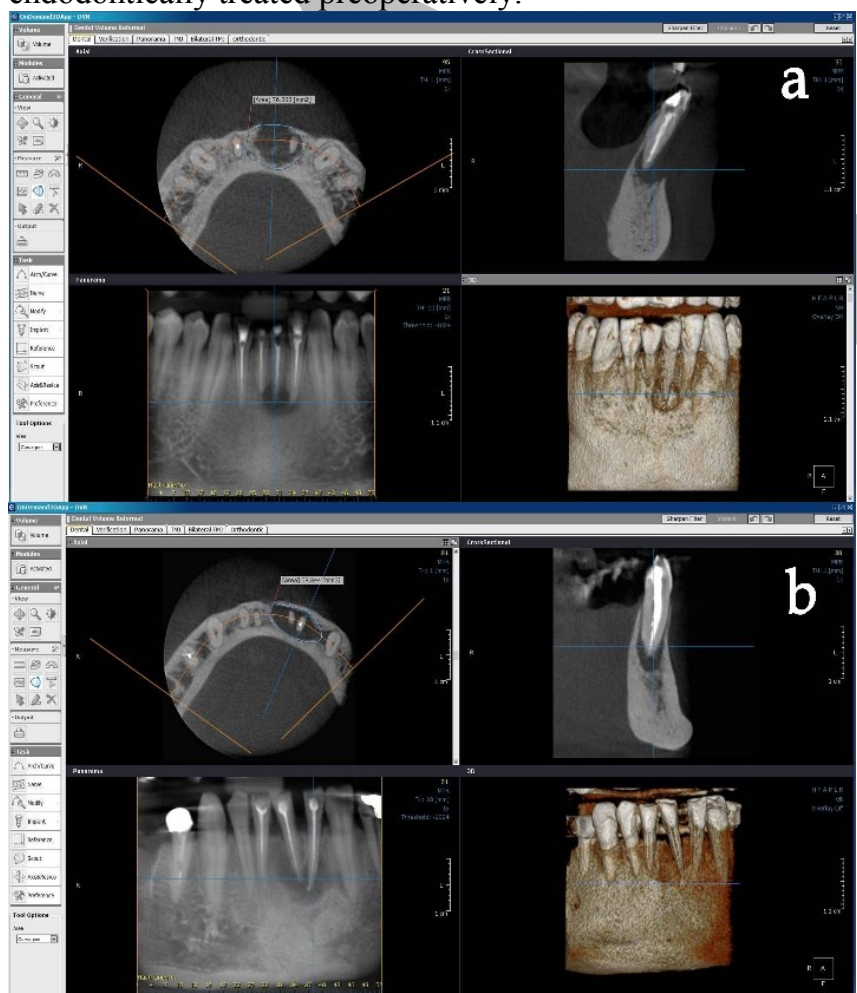

Figure 1: Preoperative C.B.C.T showing radicular cyst related to lower anterior teeth showing exact dimension of the lesion; (a) study group (b) control group

\section{Informed Consent}

Appropriate institutional ethical clearance and written informed consent were obtained.

\section{Methods}

Surgybone device (Piezosurgey ${ }^{\circledR}$ device Surgybone, Silfadent, Italy) was used in this study, which consists of a console including an electronic control circuit, an ultrasound control circuit, a piezoelectric hand piece and a peristaltic pump. Suitable tips are mounted to the piezoelectric hand piece. Three main inserts were used: SBP0100, SBP0200 and SBP0301. the following parameters was set: the power of the handpiece transducer used was 15-50 while the frequency of the handpiece transducer was 30-60 MHZ for type D2 bone and 60-100 MHZ for type D1 bone, under a sterile distilled water or physiological saline at $4{ }^{\circ} \mathrm{C}$ for better cooling effect.

\section{Surgical procedure}

The oral mucosa was painted and swabbed thoroughly with antiseptic povidine iodine solution $10 \%$ (Betadine, Nile Company for Pharmaceuticals, Cairo, Egypt) to render the surgical field free from microorganisms. Under local anesthesia, a pyramidal full thickness mucoperiosteal flap was designed with sufficient size to access the area with one tooth mesial and one tooth distal to the cystic area using Bard Parker blade number 15. The flap was reflected to expose the alveolar bone.

In the study group, the osteotomy was performed using piezosurgery. A window was designed and marked using insert SB P0200, then bone is removed using insert SB P0301 and cyst was enucleated with apicectomy to the root apices of the involved tooth. The cystic cavity was curetted using insert SB P0100 with irrigation by sterile saline solution (figure 2). While in the control group, the osteotomy was performed using fissure surgical bur mounted on a contra angled high speed hand piece under copious irrigation to cystic cavity. Cyst was enucleated using surgical curettes and apicectomy was done to involved root apices.

This was followed by proper debridement of the defect site and smoothening of bone edges with bone file then irrigation with sterile saline solution (figure 3 ). In both groups, the flap was repositioned in place and sutured using 3-0 black silk sutures.

All patients were advised to; apply cold packs extra orally intermittently and avoid hot food on the first day then apply hot fomentation on the second day.

Antibiotics were prescribed to all patients in the form of 1 gm of Amoxicillin $875 \mathrm{mg}$ and Clavulanate acid $125 \mathrm{mg}$ (Augmentin 1 gm Smithline Beecham Pharmaceutical Co., Bentford, England) twice a day for five days post-operatively and non-steroidal anti-inflammatory drug in the form of diclofenac potassium $50 \mathrm{mg}$ (Cataflam 50mg tablets, Novartis Pharma AG, Basle, Switzerland) three times daily for 7-10 days and chlorhexidine gluconate solution (Hexitol mouth wash, the Arab Drug Co., Cairo, Egypt) as a mouth rinse for a period of five days. Sutures were removed after 7 days postoperatively.

\section{Postoperative evaluation}

All patients were examined on the first, second and seventh day to evaluate pain and wound dehiscence. Pain and discomfort were examined using visual analogue scale (VAS). Patients were asked to assess the level of their average pain by placing a mark on a horizontal line that was $10 \mathrm{~cm}$ long (14). Dehiscence was evaluated through 
inspection of the wound area regarding its presence or absence. Infection was evaluated after one month for the presence of swelling, redness, discharge of pus and pain.

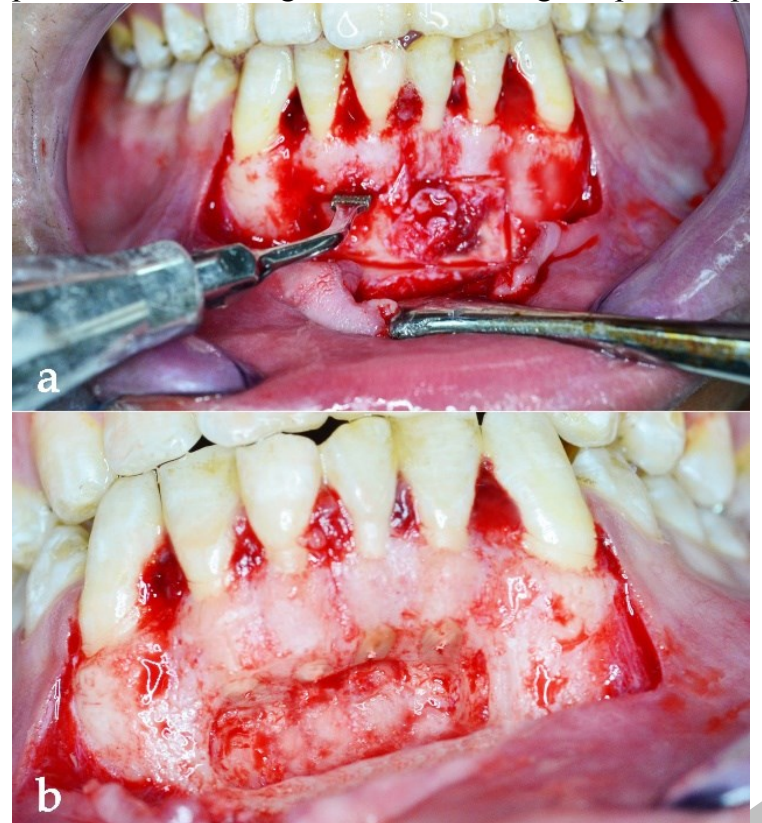

Figure 2: A photograph showing the surgical procedures of cyst enucleation and apicectomy in the study group; (a) bone cutting using piezosurgery with insert SB P0200, (b) the cavity after cyst enucleation and debridement.

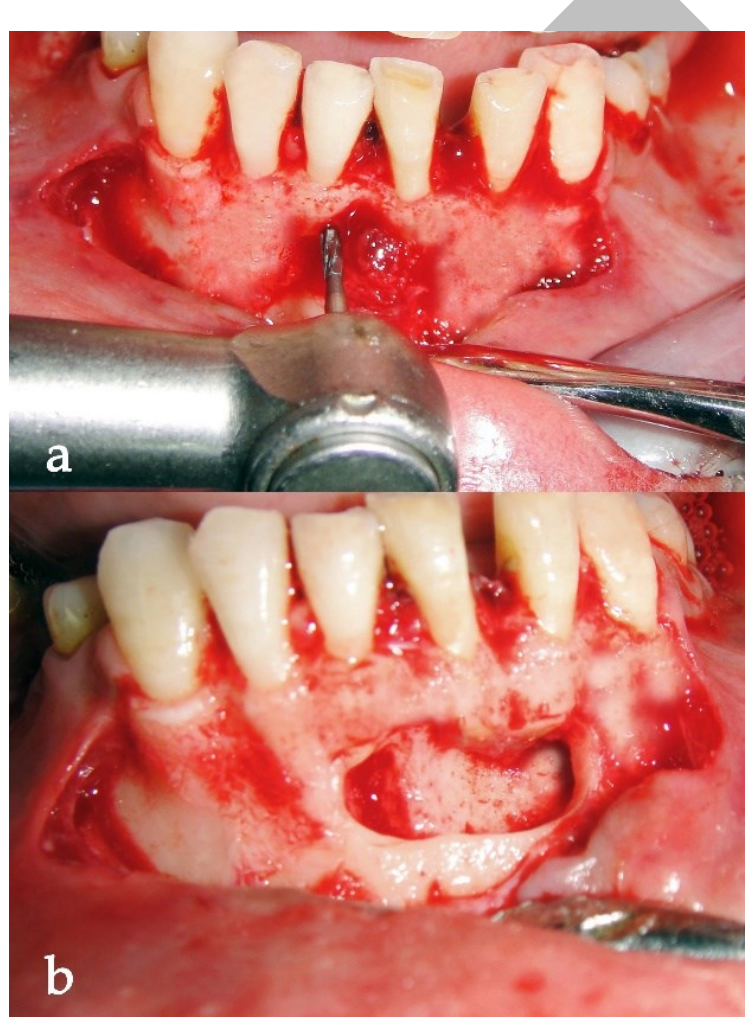

Figure 3: A photograph showing the surgical procedures of cyst enucleation and apicectomy in the control group, (a) bone cutting using surgical bur and hand piece, (b) cavity after cyst enucleation and debridement.

Cone beam computed tomography was performed on the $3^{\text {rd }}$ and $6^{\text {th }}$ month post-operatively for the assessment of healing of the bony defects regarding surface area and bone density which is calculated directly in HU using On Diamond 3DApp-DBM software system (Cypernet, Korea).

\section{STATISTICAL ANALYSIS}

The statistical analysis was performed to evaluate pain score using ANOVA and student t-test, while statistical analysis for wound dehiscence was done using chi square test and fisher's exact test. Also, statistical analysis for surface area of the defect was done using ANOVA, Post Hoc test and student t-test, while for bone density was done using Friedman Test, Wilcoxon signed ranks test and Z for Mann Whitney test.

\section{RESULTS}

The present study involved fourteen patients suffering from mandibular periapical cyst and indicated for surgical treatment by enucleation. The selected patients were randomly divided into two groups, study group and control group. The study group involved 7 patients: 4 male patients $(57,1 \%)$ and 3 female patients (42.9\%). Their ages ranged between 16 and 43 years with mean age of $27.86 \pm 11.19$ years. The control group involved 7 patients: 2 male patients $(28.6 \%)$ and 5 female patients $(71.4 \%)$. Their ages ranged between 23 and 47 years with mean age of $36.57 \pm 10.0$ years (table 1).

Table 1: Distribution of studied cases according to demographic data $(n=14)$.

\begin{tabular}{|c|c|c|c|c|c|c|}
\hline & \multicolumn{2}{|c|}{$\begin{array}{l}\text { Study } \\
(n=7)\end{array}$} & \multicolumn{2}{|c|}{$\begin{array}{c}\text { Control } \\
(\mathrm{n}=7)\end{array}$} & \multirow{2}{*}{$\begin{array}{c}\text { Test of } \\
\text { sig }\end{array}$} & \multirow{2}{*}{$\mathbf{p}$} \\
\hline & No. & $\%$ & No. & $\%$ & & \\
\hline \multicolumn{7}{|l|}{ Sex } \\
\hline Male & 4 & 57.1 & 2 & 28.6 & \multirow{2}{*}{$\chi^{2}=1.167$} & \multirow{2}{*}{0.592} \\
\hline Female & 3 & 42.9 & 5 & 71.4 & & \\
\hline \multicolumn{7}{|l|}{ Age } \\
\hline $\begin{array}{c}\text { Min. - } \\
\text { max. }\end{array}$ & \multicolumn{2}{|c|}{$16.0-43.0$} & \multicolumn{2}{|c|}{$23.0-47.0$} & \multirow{3}{*}{$Z=1.729$} & \multirow{3}{*}{0.084} \\
\hline $\begin{array}{c}\text { Mean } \pm \\
\text { SD }\end{array}$ & \multicolumn{2}{|c|}{$\begin{array}{c}27.86 \pm \\
11.19\end{array}$} & \multicolumn{2}{|c|}{$\begin{array}{c}36.57 \pm \\
10.0 \\
\end{array}$} & & \\
\hline Median & \multicolumn{2}{|c|}{21.0} & \multicolumn{2}{|c|}{35.0} & & \\
\hline
\end{tabular}

\section{Clinical evaluation}

No soft tissue damage or manipulation complexities had been recorded during the operation in both groups. In the study group intra-operative bleeding was reduced creating a better visibility of the surgical field.

\section{Wound dehiscence}

Healing was uneventful with absence of dehiscence and absence of postoperative complications. While in the control group, on the $1^{\text {st }}$ day and $2^{\text {nd }}$ day postoperatively three patients had wound dehiscence with $42 \%$, then it persisted only in two patients on $1^{\text {st }}$ week postoperatively with $28 \%$. Furthermore, there were no signs of infection after one month postoperatively in both groups.

\section{Pain index}

In the study group, Pain index recorded its highest range from 2-5 with a mean of $3.43 \pm 0.98$ on the $1^{\text {st }}$ postoperative day, on the $2^{\text {nd }}$ postoperative day it decreased with mean of $2.14 \pm 1.07$ and on the $1^{\text {st }}$ postoperative week the pain subsided completely. While on the control group, on the $1^{\text {st }}$ postoperative day the visual analogue scale recorded its highest range from 7-9 with mean of $7.71 \pm 0.95$, on the $2^{\text {nd }}$ postoperative day it decreased with mean of $5.86 \pm 1.46$ and on the $1^{\text {st }}$ postoperative week it decreased with mean of $2 \pm 1.41$.

This relation was statistically significant on the $1^{\text {st }}$ day and $2^{\text {nd }}$ postoperative follow up periods (figure 4 ). 


\section{Radiographic evaluation}

The surface area and the bone density were calculated preoperatively as baseline for measurement and at 3 and 6 months post-operatively (figure 5 and 6 ).

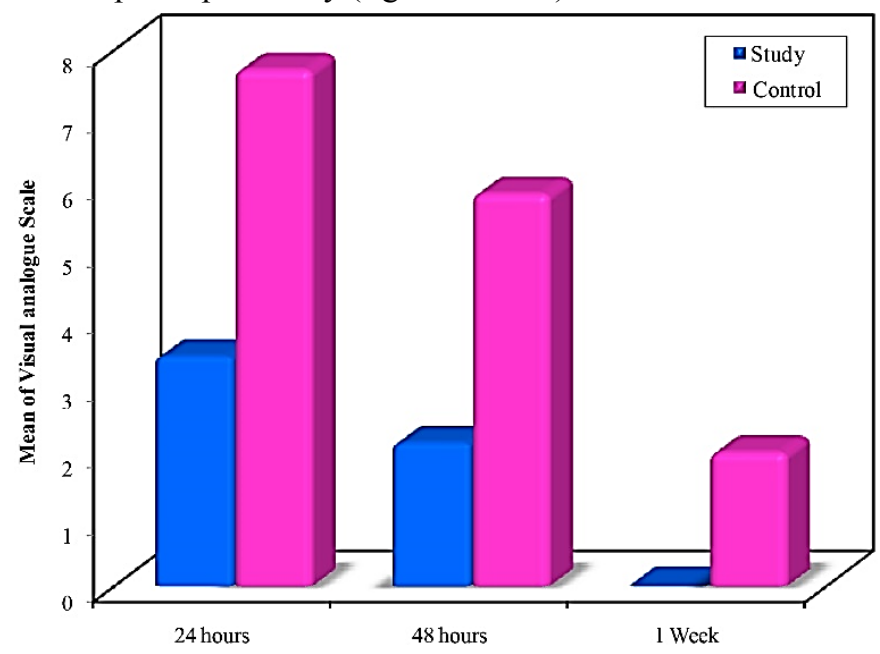

Figure 4: Charts comparing between the two studied groups according to visual analogue Scale.

\section{Surface area}

\section{Study group}

The mean surface area of the lesions preoperatively was $60.83 \pm 16.43 \mathrm{~mm}^{2}$ ranged from $40.12-81.84 \mathrm{~mm}^{2}$, on the $3^{\text {rd }}$ month postoperatively there was $47.6 \%$ size reduction of the surface area with a mean $31.87 \pm 3.36 \mathrm{~mm}^{2}$ ranged from $27.09-35.48$, and on the $6^{\text {th }}$ month the surface area was recorded as $17.39 \pm 3.44 \mathrm{~mm}^{2}$ ranged from $11.11-21.46$ with $71.4 \%$ size reduction. There was $45.4 \%$ size reduction between $3^{\text {rd }}$ month and $6^{\text {th }}$ month follow up periods. By comparing the results obtained throughout the follow up periods and preoperatively, the decrease of the surface area of the defect was statistically significant.

\section{Control group}

The surface area of the lesions ranged from $46.92-87.04$ with a mean of $59.35 \pm 14.80 \mathrm{~mm}^{2}$ preoperatively, on the $3^{\text {rd }}$ month postoperatively there was $18.5 \%$ size reduction of the surface area with a value of $48.38 \pm 10.56 \mathrm{~mm}^{2}$ ranged from $40.84-69.25$, and on the $6^{\text {th }}$ month the surface area was recorded as $32.68 \pm 11.92 \mathrm{~mm}^{2}$ ranged from $23.86-56.87$ with $44.9 \%$ size reduction.

There was $32.5 \%$ size reduction between $3^{\text {rd }}$ month and $6^{\text {th }}$ month follow up periods. By comparing the results obtained throughout the follow up periods and preoperatively, the decrease of the surface area of the defect was statistically significant.

The decrease in the surface area in the study group was greater than in the control group and the relation between two groups was statistically significant with percent of difference $34.1 \%$ on $3^{\text {rd }}$ month and $46.8 \%$ on the $6^{\text {th }}$ month (table 2).

\section{Bone density}

In the study group, the mean bone density value was $356.70 \pm 173.32 \mathrm{HU}$ preoperatively which ranged from $79.50-562.40 \mathrm{HU}$ and increased by mean $632.39 \pm$ $173.09 \mathrm{HU}$ by the $3^{\text {rd }}$ month postoperatively and ranged from $452.20-951.60 \mathrm{HU}$. By the $6^{\text {th }}$ month bone density continued to increase by mean $1091.34 \pm 193.96$ ranged from $855.10-1356.30 \mathrm{HU}$. The increase in bone density was statistically significant throughout the different follow up periods.
In the control group, the mean bone density value was $427.01 \pm 119.01 \mathrm{HU}$ preoperatively which ranged from 189.60 - 552.80HU and increased by mean473.98 \pm $151.53 \mathrm{HU}$ by the $3^{\text {rd }}$ month postoperatively and ranged from $230.54-640.0 \mathrm{HU}$. By the $6^{\text {th }}$ month bone density continued to increase by mean $666.10 \pm 193.88 \mathrm{HU}$ ranged from $343.28-867.40 \mathrm{HU}$. This relation was statistically significant.

The improvement in the bone density was greater in the study group than in the control group but this relation was only statistically significant on the $6^{\text {th }}$ month follow up period with percent of different between both groups $63.84 \%$ (table 3 ).

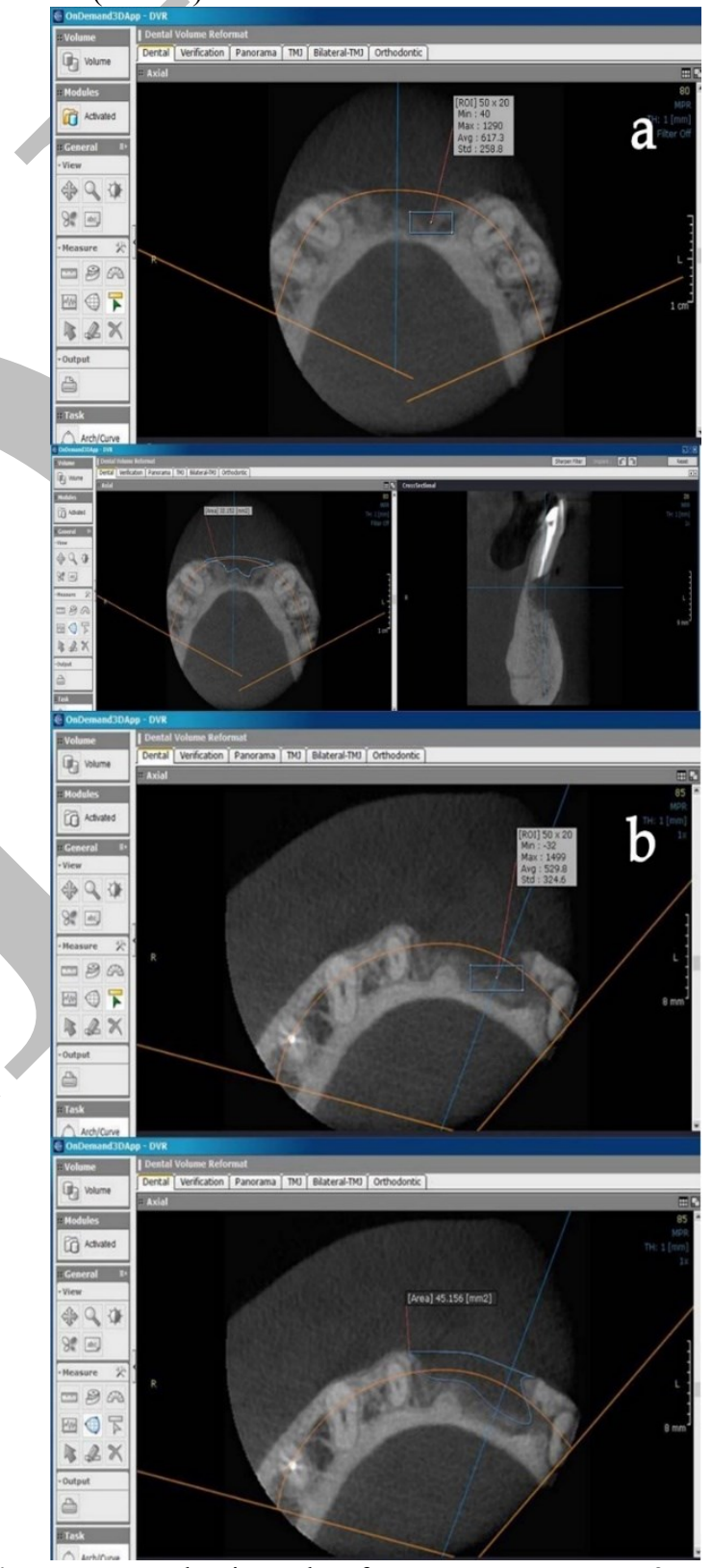

Figure 5: Bone density and surface area measurements 3 months' post-operative (a) for the study group, (b) for the control group.

\section{DISCUSSION}

Treatment success of oral and maxillofacial surgery depends on the adherence to precise biologic criteria including atraumatic surgical procedures, limited risk to the surrounding tissue, good visibility, hemostasis, and postoperative healing. In recent years, there has been increasing interest in the research and development of minimally invasive surgical procedures in oral and 
maxillofacial surgery. Most of the available instruments, such as saws, burs, and mallets and chisels, allow for rapid cutting, but do not meet all of the previously mentioned criteria. Cutting bone with surgical tools can cause tissue damage; also heat generation during osteotomy preparation is a common occurrence for oscillating, drilling, and burring devices (15).

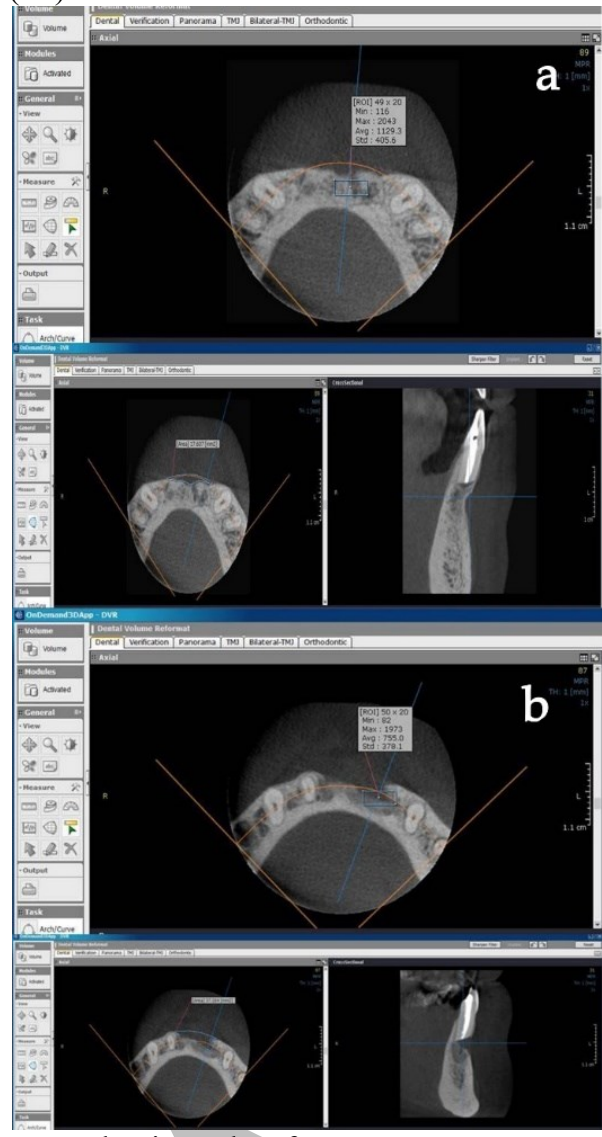

Figure6: Bone density and surface area measurements 6 months' post-operative (a) for the study group, (b) for the control group.

Piezosurgery was developed in response to the need to reach major levels of precision and intra-operative safety in bone surgery, as compared to that available by the traditional manual and motorized bone cutting instruments. It is a promising, meticulous and soft tissue sparing system for bone cutting, based on ultrasonic micro-vibrations. It was developed to overcome the limits of traditional instrumentation in oral bone surgery by modifying and improving conventional ultrasound technology (16).

In this study fourteen patients with periapical mandibular cyst and indicated for surgical treatment by enucleation, were selected from the out-patient clinic of Oral and Maxillofacial Surgery Department, Faculty of Dentistry, Alexandria University.

The selected patients were free from any uncontrolled systemic diseases or conditions that may complicate the surgical procedure or the healing process of the defect area, and to avoid any systemic influence on bone formation or bone resorption.

All patients with uncontrolled diabetes were excluded from this study because it has a negative effect on bone metabolism. This was following a study performed by Retzepi and Donos (17) in 2010, where they concluded that diabetes has been associated with reduced bone mineral density, increased risk of fractures, reduced bone mechanical properties, impaired endochondral and intramembranous bone formation and impaired microarchitectural quality of bone.

Table 2: Comparison between the two studied groups according to Surface area.

\begin{tabular}{|c|c|c|c|}
\hline & \multicolumn{3}{|c|}{ Surface area $\left(\mathrm{mm}^{2}\right)$} \\
\hline & Preoperative & 3 Months & 6 Months \\
\hline \multicolumn{4}{|l|}{ Study $(\mathrm{n}=7)$} \\
\hline Min. $-\max$. & $40.12-81.84$ & $\begin{array}{c}27.09- \\
35.48 \\
\end{array}$ & $\begin{array}{c}11.11- \\
21.46 \\
\end{array}$ \\
\hline Mean \pm SD & $\begin{array}{c}60.83 \pm \\
16.43 \\
\end{array}$ & $\begin{array}{c}31.87 \pm \\
3.36 \\
\end{array}$ & $\begin{array}{c}17.39 \pm \\
3.44 \\
\end{array}$ \\
\hline Median & 52.67 & 30.47 & 18.64 \\
\hline $\begin{array}{c}\text { \% of } \\
\text { improvement }\end{array}$ & \multicolumn{3}{|c|}{$\% 1=47.6, \% 2=71.4, \% 3=45.4$} \\
\hline \multicolumn{4}{|l|}{$\begin{array}{c}\text { Control ( } \mathbf{n} \\
=7)\end{array}$} \\
\hline Min. $-\max$. & $46.92-87.04$ & $\begin{array}{c}40.84- \\
69.25 \\
\end{array}$ & $\begin{array}{c}23.86- \\
56.87\end{array}$ \\
\hline Mean $\pm \mathrm{SD}$ & $\begin{array}{c}59.35 \pm \\
14.80 \\
\end{array}$ & $\begin{array}{c}48.38 \pm \\
10.56\end{array}$ & $\begin{array}{c}32.68 \pm \\
11.92\end{array}$ \\
\hline Median & 57.57 & 42.19 & 28.01 \\
\hline $\begin{array}{c}\text { \% of } \\
\text { improvement }\end{array}$ & \multicolumn{3}{|c|}{$\% 1=18.5, \% 2=44.9, \% 3=32.5$} \\
\hline $\mathbf{t}$ & 0.176 & $3.943^{*}$ & $3.260^{*}$ \\
\hline $\mathbf{p}$ & 0.863 & $0.005^{*}$ & $0.007^{*}$ \\
\hline $\begin{array}{c}\text { \% of } \\
\text { Difference }\end{array}$ & 2.5 & -34.1 & 46.8 \\
\hline
\end{tabular}

\section{t: Student t-test}

*: Statistically significant at $\mathrm{p} \leq 0.05$

$\% 1$ : \% of improvement from Preoperative to 3 months

$\% 2: \%$ of improvement from Preoperative to 6 months

$\% 3$ : \% of improvement from 3 months to 6 months

Table 3: Comparison between the two studied groups according to Bone Density.

\begin{tabular}{|c|c|c|c|}
\hline & \multicolumn{3}{|c|}{ Bone Density } \\
\hline & Preoperative & $\begin{array}{c}3 \\
\text { Months } \\
\end{array}$ & 6 Months \\
\hline \multicolumn{4}{|l|}{ Study $(\mathrm{n}=7)$} \\
\hline Min. $-\max$. & $\begin{array}{l}79.50- \\
562.40\end{array}$ & $\begin{array}{c}452.20- \\
951.60 \\
\end{array}$ & $\begin{array}{l}855.10- \\
1356.30\end{array}$ \\
\hline Mean \pm SD & $\begin{array}{c}356.70 \pm \\
173.32 \\
\end{array}$ & $\begin{array}{c}632.39 \pm \\
173.09 \\
\end{array}$ & $\begin{array}{c}1091.34 \pm \\
193.96\end{array}$ \\
\hline Median & 376.60 & 583.20 & 1127.30 \\
\hline $\begin{array}{c}\text { \% of } \\
\text { improvement }\end{array}$ & \multicolumn{3}{|c|}{$\% 1=50.2, \% 2=159.1, \% 3=72.6$} \\
\hline \multicolumn{4}{|l|}{$\begin{array}{c}\text { Control ( } \mathbf{n} \\
=7)\end{array}$} \\
\hline Min. - max. & $\begin{array}{c}189.60- \\
552.80\end{array}$ & $\begin{array}{c}230.54- \\
640.0\end{array}$ & $\begin{array}{c}343.28- \\
867.40\end{array}$ \\
\hline Mean $\pm \mathrm{SD}$ & $\begin{array}{c}427.01 \pm \\
119.01\end{array}$ & $\begin{array}{c}473.98 \pm \\
151.53\end{array}$ & $\begin{array}{c}666.10 \pm \\
193.88\end{array}$ \\
\hline Median & 466.60 & 439.40 & 667.80 \\
\hline $\begin{array}{c}\text { \% of } \\
\text { improvement }\end{array}$ & \multicolumn{3}{|c|}{$\% 1=11.0, \% 2=56.0, \% 3=40.5$} \\
\hline $\mathbf{Z}$ & 0.832 & 1.601 & $2.881^{*}$ \\
\hline $\mathbf{p}$ & 0.405 & 0.109 & $0.004^{*}$ \\
\hline $\begin{array}{c}\text { \% of } \\
\text { Difference }\end{array}$ & -16.47 & 33.42 & 63.84 \\
\hline
\end{tabular}

Z: Z for Mann Whitney test

$*$ : Statistically significant at $\mathrm{p} \leq 0.05$

$\% 1$ : \% of improvement from Preoperative to 3 months

$\% 2$ : \% of improvement from Preoperative to 6 months

$\% 3$ : \% of improvement from 3 months to 6 months 
In addition, heavy smokers were excluded from this study as smoking has negative effect on wound healing, also nicotine which is major component of tobacco, is cytotoxic and prevents differentiation of osteoblasts like cells to osteoblasts. This was following study performed by Levin and Schwartz-Arad in 2005 (18), and Balaji in 2008 (19).

Moreover, all patients with pace maker were excluded from this study. This was following a study performed by Erdogan $O$ in 2002 (20), they concluded that electromagnetic energy generated from a variety of dental instruments, including ultrasound scalers and cleaners, and electrosurgical instruments can cause transient inhibition of pacemaker output.

Radiology is important in the diagnostic assessment, treatment planning and follow-up of patients suspected of having dental and maxillofacial disease (21). In the present study CBCT were used for diagnosis, preoperative evaluation of the mandibular radicular cyst, and its relation to adjacent anatomical structures. This was following a study performed by Shweel M. et al in 2013 (21) who concluded that CBCT was very helpful in good preoperative planning and preparation as it helped in deciding the best approach for lesion enucleation and the incisions were precise to include the lesions.

In this study CBCT was also used in the follow up measurement of the bone density and surface area of the defect because of its accuracy, lower radiation exposure and fewer cost compared with CT This was following a study performed by Suomalainen A. in 2010 (22), concluded that CBCT was found to be a reliable tool for linear measurements when compared to Multi-slice computed tomography. Also, CBCT scanners provided adequate image quality for dental and maxillofacial imaging while delivering considerably smaller effective doses to the patient than Multi-slice computed tomography.

In the current study, there was no soft tissue damage or manipulation complexities observed in either groups. However, less bleeding was observed intra-operatively with piezosurgery due to cavitation effect created by the cooling fluid distribution and micro-vibration generated by device leading to better visibility in the operative field. This is supported by recent study conducted by Kocyigit et al in 2012 (13) who concluded that piezosurgery was found to be more successful than conventional surgery in terms of intraoperative hemorrhage as well as postoperative complications and recurrence, with no soft tissue damage or manipulation complexities in both groups.

Regarding the postoperative pain, our study revealed that from the first to the seventh day postoperatively, there was less pain in the study group as compared to the control group, this result was statistically significant on the first and second day post operatively. These findings agree with those of Pappalardo S and Guarnieri R in 2013 (23), who reported that patients in the piezosurgery group have less pain and lower VAS scale as compared to those of rotary group,

On the other hand, Jiang et al in 2015 (24), performed a systemic literature search and conducted Meta-analysis to compare piezosurgery and conventional rotary osteotomy technique in third molar extraction. They concluded that although the patients undergoing piezosurgery experienced longer surgery time, they developed less swelling, less pain, and less postoperative trismus when compared with those undergoing conventional rotary technique.

The result of the present study showed that in; study group: There was a $47.6 \%$ reduction of the surface area on the $3^{\text {rd }}$ month and $71.4 \%$ size reduction on the $6^{\text {th }}$ month postoperatively relative to the baseline preoperatively, while in the control group: there was $18.5 \%$ size reduction on the $3^{\text {rd }}$ month and $44.9 \%$ size reduction on the $6^{\text {th }}$ month postoperatively relative to the baseline preoperatively. This showed that there was more decrease in the surface area of the bone defect in the study group compared to control group, and this relation was statistically significant.

These findings agree with Vercellotti $\mathrm{T}$ in 2005 (25) who reported that piezoelectric bone surgery enhanced and accelerated bone healing because of its precise, selective and atraumatic cutting action. Also, Esteves et al in 2013 (26) performed an experimental study on rats to evaluate the dynamics of bone healing after piezosurgery and drilling osteotomy. They analyzed bone formation histologically, histomorphometrically and by means of immunohistchemical. They reported that the characteristics of the healing stages were very similar between the groups and there was no significant difference between two groups at 3, 7, and 14 days' post surgically, only at 30 days' post surgically: the amount of bone was significantly higher in the piezosurgery group.

These results were also in agreement with Carini et al (27) in 2014 where they reported that bone tissue healing showed a reduced rate of bone loss with piezoelectric instruments than with conventional devices, as well as a better healing quality by reducing patient's postoperative morbidity.

Regarding the bone density, this study revealed that from the third to the sixth months post-operatively there was an increase in the bone density in the study and the control groups, but this increase in bone density was greater in the study group than in the control group, and these results were statistically significant in the sixth month post-operatively. This corroborates with Hassan in 2010 (28) who compared post-operative effect of the piezoelectric and rotator osteotomy technique in impacted third molar. The study proved that there was minimal postoperative swelling, pain and trismus when using piezosurgery, also this study reported more increase in bone height and bone density in the piezosurgery group than in the rotatory group from the first to the sixth months postoperatively and these results were statistically significant on the first, third, and sixth months regarding the piezosurgery group.

Moreover, our results revealed that there was also a significant increase in the density of the new bone formed in the study group at 6 postoperative months that ranged from $855.10 \mathrm{HU}$ to $1356.30 \mathrm{HU}$ (Mean $\pm \mathrm{SD}, 1091.34 \pm$ 193.96HU) compared to the bone density in the control group at 6 postoperative months that ranged from $343.28 \mathrm{HU}$ to $867.40 \mathrm{HU}$ (Mean $\pm \mathrm{SD}, 666.10 \pm 193.88 \mathrm{HU}$ ), with a mean percentage of change $63.84 \%$ which is comparable to that of bone normally present in the mandible.

These results were in agreement with Norton \& Gamble in 2001 (29) who suggested that bone density can be evaluated using Hounsfield units, which are directly related to tissue attenuation coefficients taken from CT. They concluded that a difference in bone density exists for the four regions within the mouth. They recorded the mean bone density $682 \mathrm{HU}$ for 139 sites, with the mean bone density in the anterior mandible was $970 \mathrm{HU}$.

The present study proved that piezosurgery is more effective than conventional technique in enucleation of 
mandibular radicular cyst where it reduces the intraoperative and postoperative complications. The radiological analysis revealed that the bone formed in the study group was more than that in the control group, and this relation is statistically significant. Piezosurgery is safer in cutting, reliable, efficient in the initial phase of healing and controls the inflammatory process.

\section{CONCLUSIONS}

Piezosurgery is an advanced, conservative device and is effective in cyst enucleation compared to conventional procedures with burs. It provides less intraoperative complications with clear visibility of the operative field, also it reduces postoperative complications. From the present study and based on a retrospective evaluation it can be concluded that: piezosurgery enhances and accelerates bone healing because of its precise, selective and atraumatic cutting action without heat generation.

\section{STATEMENT OF CONFLICT OF INTEREST}

The authors declare that they have no conflicts of interest.

\section{REFERENCES}

1. High AS, Robinson PA, Klein CE. Discrimination of parakeratinised odontogenic keratocysts from other odontogenic and non-odontogenic cyst types by expression of a $38 \mathrm{kd}$ cellsurface glycoprotein. J Oral Pathol Med 1993; 22: 363-7.

2. Stoelinga PJ. Long-term follow-up on keratocysts treated according to a defined protocol. Int J Oral Maxillofac Surg 2001; 30: 14-25.

3. Myoung H, Hong SP, Hong SD, Lee JI, Lim CY, Choung $\mathrm{PH}$, et al. Odontogenic keratocyst: Review of 256 cases for recurrence and clinicopathologic parameters. Oral Surg Oral Med Oral Pathol Oral Radiol Endod 2001; 91: 328-33.

4. Nair PNR. Review new perspectives on radicular cysts: do they heal? Int Endod J 1998; 31: 155-60.

5. Aslan M, Şimşek G. Large residual dental cyst (A case report). Atatürk University J Vet Sci 2002; 12: 45-9.

6. Goaz PW, White SC. Oral radiology: principles and interpretation $3^{\text {rd }}$ ed. St Louis, Mo: Mosby-Year Book, 1994. 398-676.

7. Damante JH, Guerra EN, Ferreira Jr O. Spontaneous resolution of simple bone cysts. Dentomaxillofac Radiol 2002; 31: 182-6.

8. Sohn DS. Piezoelectric bone surgery presented at the $12^{\text {th }}$ Taipei congress of oral implantoglogist, Taipei, Taiwan. 2003. 27-9.

9. Horton JE, Tarpley TM, Wood LD. The healing of surgical defects in alveolar bone produced with ultrasonic instrumentation, chisel and rotator bur. Oral Surg oral Med Oral Path 1975; 39: 536-46.

10. Vercelotti T, DePaoli S, Nevins M. The piezoelectric bony window osteotomy and sinus membrane elevation: introduction of a new technique for simplification of the sinus augmentation procedure. Int $\mathrm{J}$ Periodontics Restorative Dent 2001; 21: 561-7.

11. Preti G, Martinasso G, Peirone B, Navone R, Manzella C, Muzio $\mathrm{G}$, et al. Cytokines and growth factors involved in the osseointegration of oral titanium implants positioned using piezoelectric bone surgery versus a drill technique: a pilot study in mini pigs. J Periodontol 2007; 78: 716-22.
12. Yaman Z, Suer BT. Clinical comparison of ultrasonic surgery and conventional surgical techniques for enucleating jaw cysts. Int J Oral Maxillofac Surg 2013; 42: 1462-8.

13. Kocyigit ID, Atil F, Alp YE, Tekin U, Tuz HH. Piezosurgery versus conventional surgery in radicular cyst enucleation. J Craniofac Surg 2012; 23: 1805-8.

14. Ghanbari JA, Makvandi A, Pazouki A. Quality of sleep for hospitalized patients in Rasoul-Akram hospital. Med J Islam Repub Iran 2014; 21: 73.

15. Yang B, Girod S. Efficacy of Bone Healing in Calvarial Defects Using Piezoelectric Surgical Instruments. J Craniofac Surg 2014; 25: 149-53.

16. Anuroopa P, Kishan Panicker G, Nalini MS, Bipin CR. Piezosurgery in Dentistry: A Versatile Tool in Bone Management. J Dent Sci 2014; 2: 32-7.

17. Retzepi M, Donos N. The Effect of Diabetes Mellitus on Osseous Healing. Clin Oral Implants Res 2010; 21: 673-81.

18. Levin L, Schwartz-Arad D. The effect of cigarette smoking on dental implants and related surgery. Implant Dent 2005; 14: 357-61.

19. Balaji SM. Tobacco smoking and surgical healing of oral tissues: a review. Indian J Dent Res 2008; 19: 344-8.

20. Erdogan O. Electromagnetic Interference on Pacemakers. Indian Pacing Electrophysiol J 2002; 2: 74-8.

21. Shweel M, Amer M I, ELshamanhory AF. A comparative study of cone beam CT and multi detector CT in the preoperative assessment of odontogenic cysts and tumors. Egy J Radio and Nucl Med 2013; 44: 23-32.

22. Suomalainen A. Cone beam computed tomography in oral radiology. Academic Dissertation, Department of Oral Radiology Institute of Dentistry, University of Helsinki. 2010.

23. Pappalardo S, Guarnieri R. Randomized clinical study comparing piezosurgery and conventional rotatory surgery in mandibular cyst enucleation, J Cranio Maxillofac Surg 2013; 1-6.

24. Jiang Q, Qiu Y, Yang C, Yang J, Chen M, Zhang Z. piezoelectric versus conventional Rotary Techniques for Impacted Third Molar Extraction. J Med 2015; 94: 1-7.

25. Vercellotti T, Nevins ML, Kim DM, Nevins M, Wada K, Schenk RK, et al. Osseous response following resective therapy with piezosurgery. Int J Periodontics Restorative Dent 2005; 25: 543-9.

26. Esteves JC, Marcantonio Jr E, Faloni AP, Rocha F, Marcantonio R, Wilk K, et al. Dynamics of bone healing after osteotomy with piezosurgery or conventional drilling - histomorphometrical, immunohistochemical, and molecular analysis. J Trans Med 2013; 11: 221.

27. Carini F, Saggese V, Porcao G, Baldoni M. Piezoelectric surgery in dentistry: a review, Minerva Stomatal 2014; 63: 7-34.

28. Hassan TZ. Comparative post-operative effect of the piezoelectric and rotatory osteotomy technique in impacted lower third molars surgery. Master Thesis. Oral and Maxillofacial Surgery department. Alexandria University. 2010.

29. Norton MR, Gamble C. Bone classification: An objective scale of bone density using the computerized tomography scan. Clin Oral Implants Res 2001; 12: 79-84. 